\title{
Dietary pattern by menopausal status in the UK Women's Cohort Study
}

\author{
Y. Dunneram ${ }^{1}$, V.J. Burley ${ }^{1}$, J.E. Cade ${ }^{1}$ and D.C. Greenwood ${ }^{2}$ \\ ${ }^{1}$ Nutritional Epidemiology Group, School of Food Science \& Nutrition and ${ }^{2}$ Division of Biostatistics, \\ University of Leeds, Leeds LS2 9JT, UK
}

Menopause is an important phase in a woman's life which indicates the end of reproduction and a reduction in oestrogen level and increased progesterone level which have been associated with major health implications ${ }^{(1,2)}$. It is hypothesised that diet varies considerably according to menopausal status (pre or post). However, there is limited evidence describing the diet variability by menopausal status. This study thus aims to describe the dietary pattern of women in the UK Women's Cohort Study (UKWCS) ${ }^{(3)}$ at baseline by menopausal status.

The UKWCS consists of 35,372 women aged between 35-69 years at recruitment. Diet was measured using a 217-item food frequency questionnaire. Individual foods were collapsed into 42 food groups (g/day) according to culinary use, fat and fibre content. Women were classified as premenopausal $(\geq 1$ menstrual period/year, using pills, pregnant; $n=14,645)$ or naturally postmenopausal (no menstrual period; $\mathrm{n}=17,813$ ) during the last 12 months ${ }^{(4)}$. Women who had a hysterectomy or bilateral oophorectomy prior to menopause were excluded from the analysis. Using data from 32,458 women, regression models adjusted for age and total energy intake were used to differentiate dietary pattern by menopausal status. The table below describes the differences between nutrient and food intakes of the 2 groups. In the adjusted model, postmenopausal women had higher intakes of protein, carbohydrates and fibre and lower intakes of fat than pre-menopausal women which were statistically significant. Postmenopausal women had a significantly higher consumption of a range of foods including low fat dairy products, fish, meat, fruits, vegetables, soft drinks and low calorie soft drinks. Postmenopausal women also had significantly lower intakes of tea (-28.7 g, 95\% CI: $-45 \cdot 6,-11 \cdot 8)$, alcohol, biscuits, refined pasta/rice compared to pre-menopausal women.

\begin{tabular}{|c|c|c|c|c|c|c|}
\hline \multirow[b]{2}{*}{ Daily intake } & \multicolumn{3}{|c|}{ Post v. pre-menopausal*\| } & \multicolumn{3}{|c|}{ Post v. pre-menopausal ${ }^{\dagger \|}$} \\
\hline & Mean difference & $95 \% \mathrm{CI}$ & $P$ & Mean difference & $95 \% \mathrm{CI}$ & $P$ \\
\hline$\%$ energy from protein & $0 \cdot 8$ & $0 \cdot 8,0 \cdot 9$ & $<0.001$ & $0 \cdot 4$ & $0 \cdot 3,0 \cdot 5$ & $<0.001$ \\
\hline$\%$ energy from carbohydrate & $0 \cdot 1$ & $-0 \cdot 1,0 \cdot 2$ & $0 \cdot 242$ & $0 \cdot 4$ & $0 \cdot 2,0 \cdot 6$ & $<0.001$ \\
\hline$\%$ energy from fat & $-0 \cdot 8$ & $-0.9,-0.7$ & $<0.001$ & -0.8 & $-1 \cdot 0,-0.6$ & $<0.001$ \\
\hline Fibre $(\mathrm{g})$ & $0 \cdot 4$ & $0 \cdot 2,0 \cdot 7$ & $<0.001$ & $0 \cdot 3$ & $0.05,0.6$ & 0.020 \\
\hline \multicolumn{7}{|l|}{ Foods: } \\
\hline Low fat dairy products $(\mathrm{g})$ & $9 \cdot 2$ & $7 \cdot 5,10 \cdot 8$ & $<0.001$ & $7 \cdot 8$ & $5 \cdot 4,10 \cdot 2$ & $<0 \cdot 001$ \\
\hline Meat (g) & $17 \cdot 3$ & $15 \cdot 9,18 \cdot 8$ & $<0 \cdot 001$ & $6 \cdot 8$ & $4 \cdot 7,8 \cdot 9$ & $<0 \cdot 001$ \\
\hline Fruits (g) & $31 \cdot 2$ & $25 \cdot 8,36 \cdot 6$ & $<0 \cdot 001$ & $16 \cdot 0$ & $8 \cdot 5,23 \cdot 5$ & $<0.001$ \\
\hline Vegetables (g) & $4 \cdot 6$ & $0 \cdot 3,8 \cdot 8$ & 0.034 & $11 \cdot 7$ & $6 \cdot 0,17 \cdot 5$ & $<0.001$ \\
\hline Fish \& fish dishes $(\mathrm{g})$ & $6 \cdot 4$ & $5 \cdot 8,7 \cdot 0$ & $<0.001$ & $1 \cdot 6$ & $0 \cdot 7,2 \cdot 4$ & $<0.001$ \\
\hline
\end{tabular}

* Unadjusted (model 1$) ;{ }^{\dagger}$ Age and total energy adjusted (model 2), ${ }^{\|}$Pre-menopausal as reference group

These findings suggest that the diet of premenopausal women differs to that of postmenopausal women taking into account age and total energy intake. Some of the differences observed may be due to an age cohort effect, but may also reflect improved adherence to dietary guidelines in postmenopausal women. These differences suggest that pre-menopausal women may need to improve the quality of the diet, particularly regarding fruit and vegetable intake, to support maintenance of longer term health.

1. Pokoradi AJ, Iversen L, Hannaford PC (2011) Am J Obstet Gynecol 205, 1-13.

2. Schoenaker DA, Jackson CA, Rowlands JV et al. (2014) Int J Epidemiol 43, 1542-1562.

3. Cade JE, Burley VJ, Alwan NA et al. (2015) Int J Epidemiol 0, 1-11.

4. Gold EB (2011) Obstet Gynecol Clin North Am 38, 425-440. 